\title{
Anterior Visual Pathway Meningioma
}

National Cancer Institute

\section{Source}

National Cancer Institute. Anterior Visual Pathway Meningioma. NCI Thesaurus. Code C7538.

A mening ioma that affects the anterior visual pathway. 